\title{
The effect of unemployment on social participation of spouses - Evidence from plant closures in Germany
}

\author{
Lars Kunze - Nicolai Suppa
}

July 2018

\begin{abstract}
This paper estimates the effect of an individual's unemployment on the level of social participation of their spouse. Using German panel data, it is shown that unemployment has a strong negative effect on public social activities of both directly and indirectly affected spouses. Private social activities of either spouse, however, are only found to increase, if the indirectly affected spouse is not working. Conflict prevention strategies or habituation may help to rationalise this finding. Our results imply that active labour market policies should account for spillover effects within couples and adopt a family perspective.
\end{abstract}

Keywords unemployment · social participation · plant closure · entropy balancing $\cdot$ SOEP

JEL classification $\mathrm{J} 64 \cdot \mathrm{I} 31$

\footnotetext{
We are grateful to Sebastian Garmann and Wolfram F. Richter for helpful comments and suggestions. Any remaining errors are ours.

L. Kunze

TU Dortmund, Department of Economics, 44221 Dortmund, Germany, E-mail: lars.kunze@tudortmund.de, phone: +49 231 755-3275, fax: +49 231 755-5404

N. Suppa

TU Dortmund, Department of Economics, 44221 Dortmund, Germany, E-mail: nicolai.suppa@tudortmund.de, phone: +49 231 755-4374, fax: +49 231 755-5404.
} 


\section{Introduction}

It is well-known that unemployment not only causes material hardship due to the associated loss in income, but also that it enforces the deprivation of social, psychological and non-pecuniary benefits provided by employment (Jahoda, 1982). Many empirical studies have documented the severe consequences of unemployment for individuals' subjective well-being (e.g., Kassenböhmer and Haisken-DeNew (2009)), health outcomes (e.g., Sullivan and von Wachter (2009)), ${ }^{1}$ or patterns of social participation (Kunze and Suppa, 2017). However, while the effects on the life of those directly affected are well documented, the effect on their spouses has received less attention. In fact, only a few recent studies address the consequences of unemployment for the indirectly affected spouse, see Marcus (2013) for mental health outcomes ${ }^{2}$ and Nikolova and Ayhan (2018) for individuals' lifesatisfaction. In addition, previous research also suggests that unemployment may bear a serious challenge for a relationship as it increases the probability of divorce and may cause domestic violence (e.g., Doiron and Mendolia, 2012, Anderberg et al., 2016).

The results from these studies indicate the existence of strong spillover effects from unemployment on spouses, which have to be taken into account in order to properly assess the overall (non-monetary) costs of unemployment and to better understand its nature. Yet, a systematic analysis of the effect of unemployment on social participation of the spouse, trying to identify causal effects, is missing so far. To close this gap in the literature is the aim of the present paper. $^{3}$

The importance of social participation for various economic outcomes (as e.g., better employment prospects and health, or increased growth and judicial efficiency) has been emphasised in the literature on social capital, see, e.g., Putnam (2001), Alesina and La Ferrara (2000), Bauernschuster et al. (2014). Moreover,

\footnotetext{
${ }^{1}$ Note, however, that evidence on the relationship between unemployment and health outcomes turns out to be mixed. Salm (2009) and Schmitz (2011), e.g., do not find any causal effect.

${ }^{2}$ See also Clark (2003), Bubonya et al. (2014) and Mendolia (2014) for similar analyses using different data sources.

${ }^{3}$ Classical studies about unemployment conducted in the early 1930s, long before modern welfare states have been installed, mirror both reduced social activities and increased tension within the families. Komarovsky (1940 [2004]), for instance, summarises her observations from a study in a large industrial city close to New York as follows: "The unemployed man and his wife have no social life outside the family. The extent of social isolation of the family is truly striking. This refers not only to formal club affiliations, but also to informal social life. [...] Family after family gave the same story of meagre social contacts." - (Komarovsky, 1940 [2004], p. 122). Also, in the seminal Marienthal study a woman was observed reporting "I often quarrel with my husband because he does not care about a thing any longer and is never at home. Before unemployment it was not so bad because the factory provided a distraction." - (Jahoda et al., 1974, p. 85). However, these studies are largely qualitative or crossectional quantitative with only a few observations and do not control for other variables.
} 
social participation is frequently considered to be an important dimension of human well-being which requires further scrutiny (e.g., Sen, 2000, Stiglitz et al., 2009). The consequences of unemployment for social participation of directly affected individuals, however, have recently been highlighted by Kunze and Suppa (2017). They find negative and lasting effects for public social activities but also a retreat of individuals into private life, which, in turn, limits the access to information (e.g., about vacancies) associated with a broader and more heterogeneous network. The present paper complements this literature by estimating the effect of unemployment on the spouse's level of social participation.

Identifying a causal effect of unemployment on social participation is challenging for at least two reasons. First, there may be individual unobservable effects that both affect social participation and the probability of becoming unemployed (e.g., specific personality traits), so that unobserved heterogeneity needs to be controlled for. Second, it may well be the case that an unobservable individual shock lowers social participation and thus individuals' performance on the job. Hence, estimates may be biased due to reversed causality. Using data from the German Socio-Economic Panel, we focus on plant closures as arguably exogenous reason for entry into unemployment in order to account for this latter problem. In addition, we apply a difference-in-differences matching estimator based on entropy balancing (see, e.g., Heckman et al. (1997) and Hainmueller (2012)) in order to address both selection on observables and unobservables (with time-invariant effects). Following Kunze and Suppa (2017), social participation is measured by five distinct indicators which are grouped according to whether they are carried out in private or public. Specifically, we use the frequencies of attending cultural events; cinema, pop concerts and the like; performing volunteer work (all carried out in public); social gatherings; and helping out friends (both private). In order to increases statistical power, both public and private activities are aggregated into indices by using either the simple mean or principal component (factor) analysis.

Our results show that unemployment of one spouse affects social participation patterns of both the directly and the indirectly affected spouses in a similar way. More precisely, we find significant and economic relevant decreases for public social activities, and significant increases for private social participation. The size of the effect of being unemployed due to plant closure for the indirectly affected spouse is about the same size of the effect for the directly affected spouse for public social activities and even larger for private activities. Lower public social participation for indirectly affected partners is consistent with the stigmatising effect of unemployment but may also be driven by a lower household income. 
Tests whether these findings depend on the employment status of the indirectly affected partner show that both spouses only increase private social activities, if the indirectly affected partner is not working. This finding can be rationalised by conflict prevention strategies, i.e. partners try to evade each other, or by habituation, where partners adopt routines and only undertake activities together.

Our results turn out to be robust against several assumptions and choices made. Overall, our findings highlight the importance of spillover effects within couples and imply that active labour market policies (such as supporting the unemployed in their search process and in providing them with crucial information) should be designed to address both directly and indirectly affected individuals.

The remainder of this paper is organised as follows: Section 2 describes our empirical strategy and the data. Section 3 presents our main results and several sensitivity checks. Section 4 shortly concludes.

\section{Data and Empirical Strategy}

\subsection{Empirical Strategy}

Our empirical strategy seeks to identify the average treatment effect on the treated (ATT), i.e. the average effect of unemployment on the level of social participation for those couples in which one partner loses his or her job. We adopt the framework of Heckman et al. (1997) which combines a difference-in-differences approach with matching techniques, thereby accounting for both selection on observed and unobserved variables. Similar approaches have been used by Salm (2009) and Marcus (2013). In the present paper we follow Marcus (2013) and replace conventional propensity score methods by entropy balancing.

More formally, let $D=1$ denote the treatment, i.e. an entry into unemployment due to a plant closure, and $D=0$ otherwise. Let $Y_{1}$ be the potential outcome with treatment, $Y_{0}$ without treatment, and $Y=D Y_{1}+(1-D) Y_{0}$ the observed outcome. Identification of the ATT, defined as $\tau_{A T T}=\mathrm{E}\left(Y_{1}-Y_{0} \mid D=1\right)$, is essentially based on two assumptions: a mild version of ignorability, the so-called conditional mean independence, and a mild version of the overlap assumption. Conditional mean independence requires treatment status and mean potential outcome without treatment to be independent, conditional on $X$ (the covariates), i.e. $\mathrm{E}\left(Y_{0} \mid D, X\right)=\mathrm{E}\left(Y_{0} \mid X\right)$. Accounting for selection on observables $(X)$, this assumption allows us to use the observed outcome of non-treated couples, to estimate the counterfactual outcome of treated couples. Moreover, as we focus on unem- 
ployment due to a plant closure, which can sensibly be considered to be beyond an individuals' reach, issues of reversed causality are ruled out and the weaker assumption of conditional mean independence seems justified. ${ }^{4}$

The overlap assumption requires that all combinations of conditioning variable $X$, which are actually observed among the treated, are also observed among the non-treated couples. Formally, $\mathrm{P}(D=1 \mid X)<1$, i.e. treatment is uncertain for any values of $X$.

Adopting a difference-in-differences framework further relaxes the assumption of conditional mean independence, as the potential outcome level without treatment and the treatment status itself are not required to be independent. Rather, only the mean difference over time needs to be independent of the treatment conditional on $X$, i.e. $\mathrm{E}\left(Y_{0}-Y_{0}^{\prime} \mid D, X\right)=\mathrm{E}\left(Y_{0}-Y_{0}^{\prime} \mid X\right)$, where $Y_{0}$ and $Y_{0}^{\prime}$ denote postand pre-treatment outcomes, respectively. Hence, this approach accounts for timeinvariant unobserved heterogeneity (i.e., a form of selection on unobservables) as for example personality traits or response scale interpretation. The identifying assumption can then be stated as follows: if unemployed individuals had not become unemployed, their level of social participation would have changed in the same way as the level of individuals which did not become unemployed, ${ }^{5}$ or formally,

$$
E\left(Y_{0}-Y_{0}^{\prime} \mid X, D=1\right)=E\left(Y_{0}-Y_{0}^{\prime} \mid X, D=0\right) .
$$

Note that we pool all observed unemployment entries due to a plant closure in our empirical analysis. Therefore, our setup indeed resembles the two-period case, where the treatment dummy equals 0 for all observations (treatment and control) before the treatment event, and 1 for the treated after the event. ${ }^{6}$ Thus, regressing the difference of the outcome variable on the treatment dummy in the second period is equivalent to regressing it on the difference of the treatment dummy, and can therefore be interpreted as a difference-in-differences setup (e.g., Wooldridge, 2010, p. 321).

Practically, one way to establish identification is to use propensity scores, suggesting immediately weighted estimation procedures (e.g., IPW). ${ }^{7}$ This approach

\footnotetext{
${ }^{4}$ However, it may not be completely exogenous to an individual due to anticipation effects resulting in a gradual leaving process of some workers prior the closing (Kassenböhmer and Haisken-DeNew, 2009, p. 460). The presence of such a mechanism would imply an underestimation of the treatment effect (see also the discussion in Kunze and Suppa (2017)).

${ }^{5}$ In section 3.2.3 we provide (indirect) evidence in order to support the identifying assumption.

${ }^{6}$ As a consequence, the difference in the treatment dummy equals the treatment dummy in the second period, i.e. $\Delta D=D$.

${ }^{7}$ This approach resembles the Horvitz and Thompson (1952) estimator, which uses inverse sampling probability weights to account for complex survey design or missing data problems. In fact, treatment
} 
also motivates entropy balancing, which essentially chooses weights to balance pre-specified moment conditions for covariates between treated and non-treated individuals (in our case the same mean and variance), while still remaining close to uniform weights to avoid loss of information and thus achieve efficiency (see Hainmueller, 2012). Similar to related approaches, entropy balancing also reduces model dependency through orthogonalised treatments. ${ }^{8}$ Section 3.2.1, however, shows that our main results also hold if we use inverse probability weighting, propensity score matching, and nearest neighbour matching instead of entropy balancing.

In sum, our estimator for the ATT can be described as follows:

$$
t_{A T T}=X^{\prime} W X^{-1} X^{\prime} \Delta Y
$$

where $\Delta Y$ is the vector of changes in social participation and $W$ a diagonal matrix with 1 in the diagonal cells for couples of the treatment group and entropy balancing weights in the diagonal cells for control group couples.

This setup allows us to estimate two different models. The first model reveals the effect of unemployment on changes in social participation of the same individual whose entry into unemployment is observed (the directly affected spouse). By contrast, the second model uncovers the effect of unemployment on changes in social participation of the directly affected individual's spouse (the indirectly affected spouse).

\subsection{Data and Hypotheses}

The empirical analysis uses data from the German Socio-Economic Panel, see Wagner et al. (2007). ${ }^{9}$ The analysis is restricted to the time period from 1992-2011 and focuses on cohabiting couples.

Our analysis relies on five outcome variables: The frequency of attending cultural events such as concerts, theatre, lectures, etc. (culture); attending cinema,

evaluation is often conceived as a missing data problem, as the counter-factual outcome is never observed.

${ }^{8}$ Other advantages are its versatility, as weights can be passed to almost any estimator and its computational efficiency.

${ }^{9}$ The underlying is from SOEP v30 (DOI: 10.5684/soep.v30). The data used in this paper was extracted using the Add-On package PanelWhiz for Stata. PanelWhiz (http://www.PanelWhiz.eu) was written by Dr. John P. Haisken-DeNew (john@PanelWhiz.eu). See Haisken-DeNew and Hahn (2010) for details. The PanelWhiz generated DO file to retrieve the data used here is available from us upon request. Any data or computational errors in this paper are our own. 
pop music concerts, dancing, disco, sports events (cinema); attending social gatherings (socialising); helping out friends (helping) and performing volunteer work (volunteer). These activities represent both constitutive elements of social participation and investments in social capital (e.g., Alesina and La Ferrara, 2000). They are aggregated into two indices in order to increase statistical power. Specifically, the information gathered in the respective questions and years on public (i.e., culture, cinema, volunteer) and private (i.e., socialising and helping) social activities are aggregated by using either the simple mean or principal component analysis. ${ }^{10}$ Table 1 shows our dependent variables and the waves in which information on the respective activities have been gathered. ${ }^{11}$ Table 1 also provides an overview of the conditioning variables used in our analysis. The conditioning variables originate from the pre-treatment interview and are fairly standard in the literature (e.g., Alesina and La Ferrara, 2000). They are included for both the directly and the indirectly affected spouse, except for the pre-treatment working status which is only included for indirectly affected spouses. Variables on the couple level (e.g., household income or the number of children) are only included for the directly affected spouse.

[Insert table 1 here.]

Directly affected individuals have to be aged 18 to 64 and must be employed full-time before the plant closure. Hence, directly affected individuals may either work in the private or public sector, or be self-employed. We exclude those couples in which the indirectly affected spouse experienced an involuntary job loss due to a plant closure within the same treatment period. We also exclude couples from the control group in case of an employer change or in case of separation, divorce or death of a partner. ${ }^{12}$ Thus, the control group in the first model consists of potentially directly affected individuals whereas in the second model it consists of potentially indirectly affected partners. For potentially indirectly affected spouses, we apply the same restrictions as in the treatment group construction (both before

\footnotetext{
${ }^{10}$ According to the eigenvalue criterion, the factor analysis suggests two underlying factors, in which the items culture, cinema and volunteer do only load on the first factor whereas socialising and helping only load on the second factor. See also Bauernschuster et al. (2014) for a similar aggregation procedure.

${ }^{11}$ Note that we only use the responses to these questions when they are recorded on a 4-point-scale (ranging from 'weekly' and 'monthly' to 'less frequently' and 'never').

${ }^{12}$ We have checked that none of these restrictions changes qualitatively our results. The intuition for excluding couples from the control group in case of an employer change is that social participation patterns of these couples may differ from those of the rest, for example due to differing time constraints as a result of a time-consuming new position or due to a new social environment in case the job change requires moving to another city.
} 
and after the treatment). ${ }^{13}$ Altogether, we obtain more than 20000 couples for the control group and 146 couples for the treatment group. Table 2 presents summary statistics both before and after reweighting. Note that the relatively small number of treated couples (as compared to control couples), is not an issue for our empirical approach, since we are seeking to estimate the ATT, which implies that the overlap assumption only requires $P(D=1 \mid X)<1$, but not $0<P(D=1 \mid X)<1$. Intuitively, this means that we only need to find good matches in terms of our conditioning variables for the members of the treatment group within the control group, but not vice versa.

[Insert table 2 here.]

A plant closure can occur between any two survey periods that include the social participation variables, leaving us with eight treatment periods: 1992-1994, 94-96, 96-97, 97-99, 99-01, 05-07, 07-09 and 09-11. ${ }^{14}$ Treatment effects are estimated pooled over all treatment periods.

As the focus of this paper is on cohabiting individuals, we cannot only test novel hypothesis about the indirectly affected partner, but also more specific hypothesis about the behavioural responses of the directly affected partner-conditional on her spouses characteristics, such as his or her labour force status. Theoretically, we expect unemployment to decrease public social participation of the indirectly affected partner. This hypothesis is motivated by (i) a lower household income, (ii) a social norm effect (individuals may well obtain identity utility from their partners' profession), and (iii) solidarity with and the support of their partner. Expectations regarding private social activities of the indirectly affected partner, however, are less clear cut. The indirectly affected spouse, e.g., may stay at home and provide comfort for the directly affected partner so that the level of private activities does not change much. Yet, both spouses may also spend more time with friends and relatives together, depending on the employment status of the indirectly affected spouse and thus on his available leisure time. A more detailed discussion of mechanisms for the directly affected partner is provided by Kunze and Suppa (2017).

\footnotetext{
${ }^{13}$ In particular, in the first model potentially treated individuals have to be employed in the pretreatment period, whereas their spouses may have any kind of labour force status whereas in the second model the partner of the potentially treated individual must be employed in the pre-treatment period and the indirectly affected individual may or may not be employed.

${ }^{14}$ Note that we do not consider the period 01-05 as four years are not comparable to the remaining periods. Our qualitative results, however, would be very similar if we added this period to the analysis. Similarly, dropping the observations from the period 96-97 would not change much.
} 
3 Results

\subsection{Main Results}

Panels (a) and (b) of table 3 present our main results for both public and private social activities, respectively. Each panel contains the treatment effect for the directly and the indirectly affected partner from a separate regression. Note that we did not find any gender-specific effects so that each regression does not explicitly account for the gender of the directly (indirectly) affected partner. ${ }^{15}$ As can be inferred from panel (a) (models (1) and (3)) of table 3, unemployment lowers public social activities of both the directly and indirectly affected partner. These effects are of similar magnitude for both spouses. Models (2) and (4) include an additional interaction term of the treatment indicator and the employment status of the indirectly affected partner. Clearly, as the coefficient of this interaction term turns out to be insignificant, the indirectly affected partner's employment status seems to have no role in understanding the negative overall effects for both directly and indirectly affected partners. ${ }^{16}$ Rather, the negative effects may result from a lower income level or, alternatively, from an involuntary violation of the social norm to work (as spouses may obtain identity utility from their spouses status). ${ }^{17}$

\section{[Insert table 3 here.]}

Panel (b) of table 3 presents the results for private social activities. Unemployment increases these activities for both the directly and indirectly partner (models (1) and (3)) with the impact of the spouse's unemployment being even larger for the indirectly affected partner. Allowing the treatment effect to vary with a dummy for employment of the indirectly affected partner (models (2) and (4)) shows that directly affected individuals who recently lost their job due to a plant closure only

\footnotetext{
${ }^{15}$ More specifically, we experimented with a gender dummy interaction of the treatment effect. However, the results from these estimations were not entirely clear-cut, which may be due to the small number of observations, small gender-specific effects (if existent at all), or the fact that gender roles and gender-specific behaviour are in a state of flux. Tentative results suggest a slightly stronger reduction in public social activities for both spouses if the wife loses her job. Likewise, the increase in private social activities of the indirectly affected partner appear to be somewhat larger if the husband loses its job. These results are available upon request.

${ }^{16}$ Note, however, that there is some evidence that employed indirectly affected partners reduce their public social participation more than non-working ones. While neither the treated coefficient nor its interaction turns out to be significant, the sum of these coefficients is well significantly different from zero at conventional levels of significance.

${ }^{17}$ Note, however, that Nikolova and Ayhan (2018) question the importance of income for the spouse's life satisfaction, whereas Kunze and Suppa (2017) cast doubt on the importance of income for public social activities.
} 
increase private social activities if their spouse is not employed, as the interaction effects essentially offset the main effects and the sum of main and interaction effects is not significantly different from zero. This finding could mean that he or she is either not willing or not able to engage in more private social participation activities, consistent with behavioural explanations relying on habituation (spouses may get accustomed to only undertake things together). Alternatively, previous research also highlights the challenge for a relationship associated with one spouse's unemployment (Doiron and Mendolia, 2012). Consequently, the increase of private social participation conditional on the spouse not working, may be viewed as a conflict prevention strategy, where spouses try to evade each other.

Indirectly affected spouses, however, only increase private social participation in response to their spouse's unemployment if they are not working. This finding could be the result of mutual comfort and support in order to prevent, e.g., cabin fever or depressions. In the light of an increased probability of divorce and reduced life satisfaction of both partners, it is, however, also consistent with the earlier mentioned conflict prevention strategy of evading each other, simply by meeting different friends. Unfortunately, we have no information with whom the social participation activities are carried out, which would allow us to further distinguish between these mechanisms.

What can we say about the magnitude of these effects? Consider, e.g., models (1) and (3) of table 3. The size of the effect of being unemployed due to plant closure for directly affected spouses in these estimations is on average about 70\% larger than the negative effect resulting from birth of a child (not shown), which is probably one of the most dramatic and time consuming change in a young adult's life. Similarly, the effect of unemployment for indirectly affected spouses is on average about $24 \%$ larger than the corresponding effect resulting from birth of a child. In terms of the standard deviation of the respective outcome variable, the effect of unemployment varies between $14.5 \%$ (for directly affected spouses and private social activities in specification (1)) and $24.1 \%$ (for indirectly affected spouses and private social activities in specification (3)) of a standard deviation. ${ }^{18}$

A further investigation of whether the effect of unemployment differs between different subgroups would be an interesting topic for future research with a more comprehensive database. For example, one may expect effect heterogeneity with respect to the relative age of partners, i.e., a stronger effect if partners are similar

\footnotetext{
${ }^{18}$ These calculations are based on the respective standard deviation for each outcome variable in the whole sample (not shown), which, however, approximately equals the standard deviations reported in table 2 for individuals of the control group.
} 
aged and likely have similar social networks as compared to partners which are much older/younger than one another. Tests of this hypothesis, however, showed no systematic difference between these groups. ${ }^{19}$

Overall, our results reveal that unemployment of one spouse has a differential influence on social activities of both spouses. More precisely, both directly and indirectly affected individuals reduce their participation in public social activities (a lower frequency of attending cultural events, cinema and volunteering) but at the same time intensify private social activities (an increased frequency of helping friends and neighbours and socializing) given that the indirectly affected individual is not employed. While the results for the directly affected spouse generally confirm the findings of Kunze and Suppa (2017) for couples, the novel and important aspect of this paper is that unemployment has quantitatively and qualitatively similar effects for the indirectly affected spouse. These findings illustrate that the effect of unemployment on social participation is quite substantial, which, in turn, points to potentially large costs of unemployment which have not been considered in the existing literature so far.

\subsection{Sensitivity checks}

We consider several sensitivity checks in order to demonstrate that our findings are robust to assumptions and choices made.

\subsubsection{Alternative matching techniques}

In a first step we check the robustness with respect to alternative matching techniques. More precisely, we rely on propensity score matching, inverse probability weighting and nearest neighbour matching instead of entropy balancing. Formally, these matching techniques differ from entropy balancing by assigning different weights to each observation. For example, nearest neighbour matching determines possible matches by the distance in the propensity score and sets equal weights to all matched neighbours. By contrast, the weights for control group observations in inverse probability weighting are given by $1 /(1-P S(X))$, where $P S(X)$ is the propensity score. Table 4 shows the results for propensity score matching (columns (1) and (4)), inverse probability weighting (columns (2) and (5)) and nearest neighbour matching (columns (3) and (6)), respectively. Clearly, both the

\footnotetext{
${ }^{19}$ These results are available upon request.
} 
qualitative and quantitative effects are very similar to the results in the main specifications. Hence, our main results turn out to be robust against alternative matching techniques.

[Insert table 4 here.]

\subsubsection{Multiple hypotheses}

Since we use the same data set to test multiple hypotheses, our results may suffer from an increased risk of false positives, i.e. erroneously rejected null hypotheses of the true effect being zero (type-I-errors). More specifically, we address a family of eight hypotheses in our main analysis, i.e. the combinations of directly and indirectly affected spouses, private and public activities, and outcome indices constructed by simple mean and by factor analysis. However, as the number of tested hypotheses is relatively small compared to other research that is aware of multiple hypotheses testing, we expect this problem not to be particular severe. ${ }^{20}$

Previous research in this field has proposed several procedures to adjust pvalues for testing multiple hypotheses (see, e.g., Westfall and Young (1993) for an overview). Table 3 presents the adjusted values resulting from from the TukeyCiminera-Heyse (TCH) approach, which controls the so-called family-wise error rate (FWER) but which is still easy to implement. Clearly, as compared to the unadjusted p-values (not shown), only one coefficient looses statistical significance at $p<.1$. Therefore, we conclude that in our case multiple hypotheses do not represent a major threat to the main results. ${ }^{21}$

\subsubsection{Placebo regression}

A common approach to assess the credibility of the assumptions made is to run placebo regressions. The idea behind this approach is that no effect should be observed, if no treatment took place. Hence, a common strategy adopted along these lines is to exploit the timing of the events. In this respect, we follow Marcus (2013) and show the results from a placebo regression in which the treatment is assumed to take place two years (resp. one year) earlier and which uses weights for conditioning variables from the last interview with social participation data before the hypothetical job loss. Specifically, we regress our treatment indicator

\footnotetext{
${ }^{20}$ In the early intervention studies, for instance, it is common to test dozens or even hundreds of outcomes.

${ }^{21}$ Note that this conclusion is robust to alternative adjustment procedures (the results from these procedures are available upon request).
} 
and lagged control variables on the lagged dependent variables. As can be inferred from columns (1) and (4) of table 5, all effects are small and insignificant, which, in turn, lends support to the identifying assumption of similar social participation patterns of treated and untreated individuals before the occurrence of the treatment.

[Insert table 5 here.]

\subsection{Further results}

\subsubsection{Results for single outcomes}

In order to increases statistical power, our main results are based on aggregated indices for both public and private activities. For the sake of completeness, however, table 6 also presents the results of our main specification when using each single activity (i.e., culture, cinema, volunteering, socialising and helping) as an outcome variable. For directly affected spouses, as can be inferred from table 6 , the coefficient of unemployment is significant and negative for attending cultural events and cinema, and for voluntary work. For indirectly affected spouses, however, the respective coefficient is significant and negative for voluntary work and positive for socialising and helping. In general, these findings mirror our main results, even though we do not find significant effects for some of the specific activities. $^{22}$

[Insert table 6 here.]

\subsubsection{All plant closures}

The main focus of our analysis is on the effect of unemployment, and not on job loss or plant closures per se. However, research on the effects of unemployment is closely related to research on the consequences of job loss. To allow for comparisons with this line of research, we also present our main estimation results when the treatment group includes all couples that experienced a plant closure (but not necessarily an unemployment spell). ${ }^{23}$ Columns (2) and (5) of table 5 show that the effects for both the directly and indirectly affected spouse are much smaller as compared to the main results and become insignificant in many cases.

\footnotetext{
${ }^{22}$ One explanation might be a lack of variation in the dependent variable.

${ }^{23}$ See, e.g., Marcus (2013) for a related discussion on health outcomes.
} 
Hence, the actual experience of unemployment, related to a job loss turns out to be vital for the overall effect on social participation. More specifically, behavioural responses seem to differ between individuals who change their job and individuals who become unemployed. Likely explanations are differing time constraints, financial concerns, or identity utility.

\subsubsection{All reasons for unemployment}

Finally, to further probe the plausibility of our assumptions, we consider the effect of unemployment irrespective of the reason for entering unemployment. Since we now allow for voluntary and other endogenous unemployment entries (e.g., due to "own resignation" or "mutual agreement"), we expect the conditional independence in means assumption to be violated and thus a substantial change of the results. ${ }^{24}$ Columns (3) and (6) of table 5 demonstrate that, when considering all possible reasons, effects are much smaller for public activities and even insignificant for private activities. Voluntary unemployed may feel no need to adjust their public social activities, and may also not need any backup from friends or family, e.g., due to having sufficient resources for consumption smoothing and/or better job prospects, or because the are confronted with a weaker norm to work. ${ }^{25}$ In short, it is plausible to expect different behavioural responses for voluntary and exogenous unemployment entries and we conclude that the distinction of different reasons for unemployment entries is essential for a credible identification strategy in similar study designs.

\section{Concluding Remarks}

This is the first paper to estimate the effect of unemployment on social participation of indirectly affected spouses. Using German panel data, we find negative (positive) and significant effects on public (private) social participation activities. However, our results also suggest that changes in private social participation vary with the employment status of the indirectly affected partner. Our findings highlight the importance of spillover effects within couples and imply that the previous literature has underestimated the (non-monetary) costs of unemployment as the consequences for social participation of indirectly affected spouses have not been

\footnotetext{
${ }^{24}$ Reasons for unemployment entries have already received some attention in previous research, see, e.g., Winkelmann and Winkelmann (1998) or Kassenböhmer and Haisken-DeNew (2009).

${ }^{25}$ Results from a more detailed analysis for different reasons of unemployment are available upon request.
} 
taken into account so far. Moreover, they imply that active labour market policies should be designed to address both directly and indirectly affected spouses with a special emphasis on maintaining family and social resources. As suggested, e.g., by family stress theory, changes in social participation can be considered as being part of coping strategies with unemployment. Future research should provide a better understanding of commonly adopted coping strategies and their effects on individuals well-being, the stock of social capital and labour market outcomes for both directly and indirectly affected spouses.

Finally, we shortly discuss two limitations of our analysis. First, due to the small number of observations in the treatment group, the analysis of effect heterogeneity is difficult to accomplish with the available data set. A more thorough analysis of possible differences between subgroups (e.g., gender differences) may be an interesting topic for future research as more data become available. Second, with the given information about social participation activities, we are not able to analyse with whom social activities are carried out. This prevents us from further analysing the mechanisms behind our findings. While we provide some intuition, such as habituation effects, conflict prevention strategies or income effects, there is room for alternative explanations.

\section{References}

Alesina, A. and La Ferrara, E., 2000. Participation In Heterogeneous Communities, The Quarterly Journal of Economics, 115 (3), 847-904.

Anderberg, D., Rainer, H., Wadsworth, J., and Wilson, T., 2016. Unemployment and domestic violence: Theory and evidence, The Economic Journal, 126 (597), 1947-1979.

Bauernschuster, S., Falck, O., and Woessmann, L., 2014. Surfing alone? The internet and social capital: Evidence from an unforeseeable technological mistake, Journal of Public Economics, 117 (C), 73-89.

Bubonya, M., Cobb-Clark, D.A., and Wooden, M., 2014. A Family Affair: Job Loss and the Mental Health of Spouses and Adolescents, Melbourne Institute Working Paper Series 23/14, Melbourne Institute of Applied Economic and Social Research, The University of Melbourne.

Clark, A.E., 2003. Unemployment as a Social Norm: Psychological Evidence from Panel Data, Journal of Labor Economics, 21 (2), 323-351.

Doiron, D. and Mendolia, S., 2012. The impact of job loss on family dissolution, Journal of Population Economics, 25, 367-398. 
Hainmueller, J., 2012. Entropy balancing for causal effects: A multivariate reweighting method to produce balanced samples in observational studies, Political Analysis, 20, 25-46.

Haisken-DeNew, J.P. and Hahn, M., 2010. Panelwhiz: Efficient data extraction of complex panel data sets: An example using the german SOEP, Schmollers Jahrbuch, 130 (4), 643-654.

Heckman, J.J., Ichimura, H., and Todd, P.E., 1997. Matching as an econometric evaluation estimator: Evidence from evaluating a job training programme, The Review of Economic Studies, 24, 605-654.

Horvitz, D.G. and Thompson, D.J., 1952. A generalization of sampling without replacement from a finite universe, Journal of the American Statistical Association, 47 (260), 663-685.

Jahoda, M., 1982. Employment and Unemployment: A Social-Psychological Analysis, The Psychology of Social Issues, Cambridge University Press.

Jahoda, M., Lazarsfeld, P.F., and Zeisel, H., 1974. Marienthal: The Sociography of an Unemployed Community, Social science paperbacks, Transaction Publishers.

Kassenböhmer, S.C. and Haisken-DeNew, J.P., 2009. You're fired! The Causal Negative Effect of Entry Unemployment on Life Satisfaction, Economic Journal, 119, 448-462.

Komarovsky, M.a., 1940 [2004]. The Unemployed Man and His Family: The Effect of Unemployment Upon the Status of the Man in Fifty-nine Families, Classics in gender studies, AltaMira Press.

Kunze, L. and Suppa, N., 2017. Bowling alone or bowling at all? the effect of unemployment on social participation, Journal of Economic Behavior \& Organization, 133, 213-235.

Marcus, J., 2013. The effect of unemployment on the mental health of spouses Evidence from plant closures in Germany, Journal of Health Economics, 32 (3), 546-558.

Mendolia, S., 2014. The impact of husband's job loss on partners' mental health, Review of Economics of the Household, 12 (2), 277-294.

Nikolova, M. and Ayhan, S.H., 2018. Your Spouse Is Fired! How Much Do You Care?, Journal of Population Economics, forthcoming.

Putnam, R., 2001. Bowling Alone, Simon \& Schuster.

Salm, M., 2009. Does job loss cause ill health?, Health Economics, 18, 1075-1089.

Schmitz, H., 2011. Why are the unemployed in worse health? The causal effect of unemployment on health, Labour Economics, 18 (1), 71-78. 
Table 1 Variable Definitions

\begin{tabular}{|c|c|c|c|}
\hline Variable & Question / Definition & $\mathrm{D}$ & I \\
\hline Activity Variables & $\begin{array}{l}4 \text { categories for each variable } \\
\text { (at least once a week, at least once a month, less often, never) } \\
\text { gathered in: } 92,94,96,97,99,01,05,07,09,11\end{array}$ & & \\
\hline Cinema & $\begin{array}{l}\text { 'Going to the movies, pop music concerts, dancing, disco, sports } \\
\text { events' }\end{array}$ & & \\
\hline Culture & 'Going to cultural events (such as concerts, theatre, lectures, etc.)' & & \\
\hline Volunteer & 'Volunteer work in clubs or social services' & & \\
\hline Socialise & 'Meeting with friends, relatives or neighbours' & & \\
\hline Helping & 'Helping out friends, relatives or neighbours' & & \\
\hline \multicolumn{4}{|l|}{ Conditioning Variables } \\
\hline Age & $\begin{array}{l}\text { in years, } 4 \text { categories } \\
\text { (Age } \leq 30,31 \leq \text { Age } \leq 40,41 \leq \text { Age } \leq 50 \text {, Age } \geq 51 \text { ) }\end{array}$ & Yes & Yes \\
\hline Female & $1=$ Yes, $0=$ No & Yes & Yes \\
\hline Years of education & Number of years & Yes & Yes \\
\hline Work disability & $1=$ Yes, $0=$ No & Yes & Yes \\
\hline Partner employed & $1=$ Yes, $0=$ No & & Yes \\
\hline \multicolumn{4}{|l|}{ Couple Information } \\
\hline Household Income & Log net real household equivalence income (in Euro) & Yes & \\
\hline Children & 4 categories (No children, 1 child, 2 children, $\geq 3$ children & Yes & \\
\hline Child Birth & $1=$ Birth of child during the last year, $0=$ otherwise & Yes & \\
\hline Care needing person in household & $1=$ Yes, $0=$ No & Yes & \\
\hline West Germany & $1=$ West Germany, $0=$ East Germany & Yes & \\
\hline Survey year & 8 categories $(1992,1994,1996,1997,1999,2005,2007,2009)$ & Yes & \\
\hline
\end{tabular}

Sen, A.K., 2000. Social exclusion: Concept, application, and scrutiny, Social development papers, vol. No. 1, Manila: ADB.

Stiglitz, J.E., Sen, A.K., and Fitoussi, J.P., 2009. Report by the commission on the measurement of economic performance and social progress, Tech. rep., Commission on the Measurement of Economic Performance and Social Progress.

Sullivan, D. and von Wachter, T., 2009. Job displacement and mortality: An analysis using administrative data, The Quarterly Journal of Economics, 124, 12651306.

Wagner, G.G., Frick, J.R., and Schupp, J., 2007. The German socio-economic panel study (soep): Scope, evolution and enhancements, Schmollers Jahrbuch, 127 (1), 139-169.

Westfall, P.H. and Young, S.S., 1993. Resampling-Based Multiple Testing: Examples and Methods for p-Value Adjustment, New York: Jouhn Wiley and Sons.

Winkelmann, L. and Winkelmann, R., 1998. Why Are the Unemployed So Unhappy? Evidence from Panel Data, Economica, 65 (257), 1-15.

Wooldridge, J.M., 2010. Econometric Analysis of Cross Section and Panel Data, Cambridge MA: MIT Press.

$<$ 
Table 2 Summary Statistics

\begin{tabular}{|c|c|c|c|c|c|c|}
\hline & \multicolumn{2}{|c|}{ Treated } & \multicolumn{4}{|c|}{ Control } \\
\hline & \multirow[b]{2}{*}{ Mean } & \multirow[b]{2}{*}{$\begin{array}{l}\text { Std. } \\
\text { Dev. }\end{array}$} & \multicolumn{2}{|c|}{ Unbalanced } & \multicolumn{2}{|c|}{ Balanced } \\
\hline & & & Mean & $\begin{array}{l}\text { Std. } \\
\text { Dev. }\end{array}$ & Mean & $\begin{array}{l}\text { Std. } \\
\text { Dev. }\end{array}$ \\
\hline \multicolumn{7}{|l|}{ Directly affected spouse } \\
\hline Age $\leq 30$ & 0.116 & $(0.322)$ & 0.122 & $(0.327)$ & 0.117 & $(0.322)$ \\
\hline Age $31-40$ & 0.205 & $(0.405)$ & 0.295 & $(0.456)$ & 0.205 & $(0.404)$ \\
\hline Age $41-50$ & 0.322 & $(0.469)$ & 0.333 & $(0.471)$ & 0.322 & $(0.467)$ \\
\hline Age $50+$ & 0.356 & $(0.481)$ & 0.250 & $(0.433)$ & 0.356 & $(0.479)$ \\
\hline Female & 0.541 & $(0.500)$ & 0.548 & $(0.498)$ & 0.540 & $(0.498)$ \\
\hline Years of Education & 11.216 & $(2.037)$ & 12.191 & $(2.697)$ & 11.189 & $(2.035)$ \\
\hline Work Disability & 0.055 & $(0.228)$ & 0.053 & $(0.223)$ & 0.055 & $(0.228)$ \\
\hline \multicolumn{7}{|l|}{ Indirectly affected spouse } \\
\hline Age $\leq 30$ & 0.123 & $(0.330)$ & 0.125 & $(0.331)$ & 0.124 & $(0.330)$ \\
\hline Age $31-40$ & 0.199 & $(0.400)$ & 0.275 & $(0.447)$ & 0.199 & $(0.399)$ \\
\hline Age $41-50$ & 0.301 & $(0.460)$ & 0.332 & $(0.471)$ & 0.301 & $(0.459)$ \\
\hline Age $50+$ & 0.377 & $(0.486)$ & 0.267 & $(0.443)$ & 0.376 & $(0.484)$ \\
\hline Female & 0.459 & $(0.500)$ & 0.452 & $(0.498)$ & 0.458 & $(0.498)$ \\
\hline Years of Education & 11.086 & $(1.760)$ & 12.147 & $(2.736)$ & 11.060 & $(1.760)$ \\
\hline Work Disability & 0.144 & $(0.352)$ & 0.085 & $(0.278)$ & 0.144 & $(0.351)$ \\
\hline Partner Employed & 0.616 & $(0.488)$ & 0.714 & $(0.452)$ & 0.615 & $(0.487)$ \\
\hline Log Net Real HH Eq. Income (in Euro) & 7.285 & $(0.336)$ & 7.487 & $(0.413)$ & 7.268 & $(0.335)$ \\
\hline \multicolumn{7}{|l|}{ Household Variables } \\
\hline No Children & 0.555 & $(0.499)$ & 0.505 & $(0.500)$ & 0.555 & $(0.497)$ \\
\hline 1 child & 0.226 & $(0.420)$ & 0.236 & $(0.425)$ & 0.226 & $(0.418)$ \\
\hline 2 children & 0.151 & $(0.359)$ & 0.199 & $(0.399)$ & 0.151 & $(0.358)$ \\
\hline $3+$ children & 0.068 & $(0.253)$ & 0.060 & $(0.237)$ & 0.069 & $(0.253)$ \\
\hline Shock: Child born & 0.014 & $(0.117)$ & 0.028 & $(0.165)$ & 0.014 & $(0.116)$ \\
\hline Care needing person in $\mathrm{HH}$ & 0.027 & $(0.164)$ & 0.017 & $(0.130)$ & 0.027 & $(0.163)$ \\
\hline West Germany & 0.486 & $(0.502)$ & 0.698 & $(0.459)$ & 0.485 & $(0.500)$ \\
\hline 1992 & 0.329 & $(0.471)$ & 0.114 & $(0.318)$ & 0.329 & $(0.470)$ \\
\hline 1994 & 0.226 & $(0.420)$ & 0.118 & $(0.323)$ & 0.226 & $(0.418)$ \\
\hline 1996 & 0.144 & $(0.352)$ & 0.142 & $(0.349)$ & 0.144 & $(0.351)$ \\
\hline 1997 & 0.055 & $(0.228)$ & 0.110 & $(0.313)$ & 0.055 & $(0.228)$ \\
\hline 1999 & 0.027 & $(0.164)$ & 0.113 & $(0.316)$ & 0.027 & $(0.163)$ \\
\hline 2005 & 0.055 & $(0.228)$ & 0.145 & $(0.352)$ & 0.055 & $(0.228)$ \\
\hline 2007 & 0.089 & $(0.286)$ & 0.137 & $(0.344)$ & 0.089 & $(0.285)$ \\
\hline 2009 & 0.075 & $(0.265)$ & 0.121 & $(0.326)$ & 0.075 & $(0.264)$ \\
\hline \multicolumn{7}{|c|}{ Social participation of directly affected spouse } \\
\hline Public (simple man) & 1.58 & $(0.509)$ & 1.79 & $(0.549)$ & & \\
\hline Private (simple man) & 2.68 & $(0.603)$ & 2.78 & $(0.627)$ & & \\
\hline Public (factor analysis) & -0.33 & $(0.886)$ & 0.04 & $(0.934)$ & & \\
\hline Private (factor analysis) & -0.13 & $(0.936)$ & -0.01 & $(0.966)$ & & \\
\hline \multicolumn{7}{|c|}{ Social participation of indirectly affected spouse } \\
\hline Public (simple man) & 1.64 & $(0.547)$ & 1.79 & $(0.565)$ & & \\
\hline Private (simple man) & 2.59 & $(0.640)$ & 2.78 & $(0.636)$ & & \\
\hline Public (factor analysis) & -0.22 & $(0.914)$ & 0.04 & $(0.941)$ & & \\
\hline Private (factor analysis) & -0.27 & $(0.982)$ & -0.01 & $(0.968)$ & & \\
\hline Observations & 146 & & 23195 & & 23195 & \\
\hline
\end{tabular}

Notes: Data from SOEP 1992-2011. Summary statistics for treated couples, all control couples and matched control couples. The first four columns present means and standard deviations before treatment for treated and controls. The last two columns show means and standard deviations for the reweighted control group according to entropy balancing. 
Table 3 Unemployment and Social Participation - Main results

\begin{tabular}{|c|c|c|c|c|}
\hline \multirow[b]{2}{*}{ (a) Public Social Participation } & \multicolumn{2}{|c|}{ Simple Mean } & \multicolumn{2}{|c|}{ Factor Analysis } \\
\hline & (1) & $(2)$ & (3) & (4) \\
\hline \multicolumn{5}{|l|}{ Directly affected partner } \\
\hline Treated & $\begin{array}{c}-0.0949^{* * *} \\
(-3.12)\end{array}$ & $\begin{array}{c}-0.0874^{*} \\
(-1.80)\end{array}$ & $\begin{array}{c}-0.187^{* * * *} \\
(-3.43)\end{array}$ & $\begin{array}{c}-0.186^{* *} \\
(-2.10)\end{array}$ \\
\hline Ind. aff. partner employed & $\begin{array}{c}-0.00629 \\
(-0.16)\end{array}$ & $\begin{array}{c}-0.000954 \\
(-0.04)\end{array}$ & $\begin{array}{c}-0.000842 \\
(-0.01)\end{array}$ & $\begin{array}{c}0.000348 \\
(0.01)\end{array}$ \\
\hline Treated $\times$ Ind. aff. partner employed & & $\begin{array}{c}-0.0122 \\
(-0.19)\end{array}$ & & $\begin{array}{c}-0.00272 \\
(-0.02)\end{array}$ \\
\hline TCH adj. p-value for $\widehat{\beta}_{\text {Treated }}$ & 0.005 & & 0.002 & \\
\hline \multicolumn{5}{|l|}{ Indirectly affected partner } \\
\hline Treated & $\begin{array}{c}-0.0901^{* *} \\
(-2.39)\end{array}$ & $\begin{array}{c}-0.0455 \\
(-0.84)\end{array}$ & $\begin{array}{c}-0.167^{* * * *} \\
(-2.63)\end{array}$ & $\begin{array}{c}-0.0977 \\
(-1.02)\end{array}$ \\
\hline Ind. aff. partner employed & $\begin{array}{c}-0.00902 \\
(-0.20)\end{array}$ & $\begin{array}{c}0.0227 \\
(0.85)\end{array}$ & $\begin{array}{c}-0.00831 \\
(-0.11)\end{array}$ & $\begin{array}{l}0.0410 \\
(0.88)\end{array}$ \\
\hline Treated $\times$ Ind. aff. partner employed & & $\begin{array}{c}-0.0726 \\
(-0.99)\end{array}$ & & $\begin{array}{l}-0.113 \\
(-0.89)\end{array}$ \\
\hline TCH adj. p-value for $\widehat{\beta}_{\text {Treated }}$ & 0.048 & & 0.024 & \\
\hline \multicolumn{5}{|l|}{ (b) Private Social Participation } \\
\hline \multicolumn{5}{|l|}{ Directly affected partner } \\
\hline Treated & $\begin{array}{c}0.0906^{*} \\
(1.95)\end{array}$ & $\begin{array}{c}0.213^{* * *} \\
(3.01)\end{array}$ & $\begin{array}{c}0.157^{* *} \\
(2.18)\end{array}$ & $\begin{array}{c}0.331^{* * *} \\
(2.99)\end{array}$ \\
\hline Ind. aff. partner employed & $\begin{array}{c}-0.0524 \\
(-0.92)\end{array}$ & $\begin{array}{c}0.0348 \\
(0.90)\end{array}$ & $\begin{array}{c}-0.0654 \\
(-0.74)\end{array}$ & $\begin{array}{c}0.0580 \\
(0.96)\end{array}$ \\
\hline Treated $\times$ Ind. aff. partner employed & & $\begin{array}{c}-0.199^{* *} \\
(-2.11)\end{array}$ & & $\begin{array}{c}-0.282^{*} \\
(-1.92)\end{array}$ \\
\hline TCH adj. p-value for $\widehat{\beta}_{\text {Treated }}$ & 0.139 & & 0.081 & \\
\hline \multicolumn{5}{|l|}{ Indirectly affected partner } \\
\hline Treated & $\begin{array}{c}0.141^{* * * *} \\
(2.80)\end{array}$ & $\begin{array}{c}0.317^{* * * *} \\
(3.62)\end{array}$ & $\begin{array}{c}0.233^{* * * *} \\
(3.03)\end{array}$ & $\begin{array}{c}0.487^{* * *} \\
(3.64)\end{array}$ \\
\hline Ind. aff. partner employed & $\begin{array}{c}-0.0861 \\
(-1.52)\end{array}$ & $\begin{array}{c}0.0395 \\
(0.94)\end{array}$ & $\begin{array}{l}-0.120 \\
(-1.41)\end{array}$ & $\begin{array}{c}0.0609 \\
(0.95)\end{array}$ \\
\hline Treated $\times$ Ind. aff. partner employed & & $\begin{array}{c}-0.287^{* * * *} \\
(-2.74)\end{array}$ & & $\begin{array}{c}-0.413^{* * * *} \\
(-2.58)\end{array}$ \\
\hline TCH adj. p-value for $\widehat{\beta}_{\text {Treated }}$ & 0.015 & & 0.007 & \\
\hline \multicolumn{5}{|c|}{$\begin{array}{l}\text { Notes: Data from SOEP 1992-2011. Indicated levels of significance are }{ }^{*} p<0.1,{ }^{* *} p<0.05,{ }^{* * *} p<0.01 \text {, t-statistics } \\
\text { based on clustered standard errors (on the couple level) in parentheses. The table presents the effect of one spouse's } \\
\text { entry into unemployment on the level of social participation of both spouses for private and public activities. The } \\
\text { regressions in each column and panel are based on the matching difference-in-differences estimator with more than } \\
20,000 \text { couples in the control group and } 146 \text { couples in the treatment group and include all conditioning variables } \\
\text { listed in table } 2 \text {. The table also contains p-values of treated coefficients adjusted for multiple hypothesis testing using } \\
\text { the Tukey-Ciminera-Heyse approach (eight hypotheses). }\end{array}$} \\
\hline
\end{tabular}


Table 4 Robustness of the Estimates of the ATT to Alternative Estimators

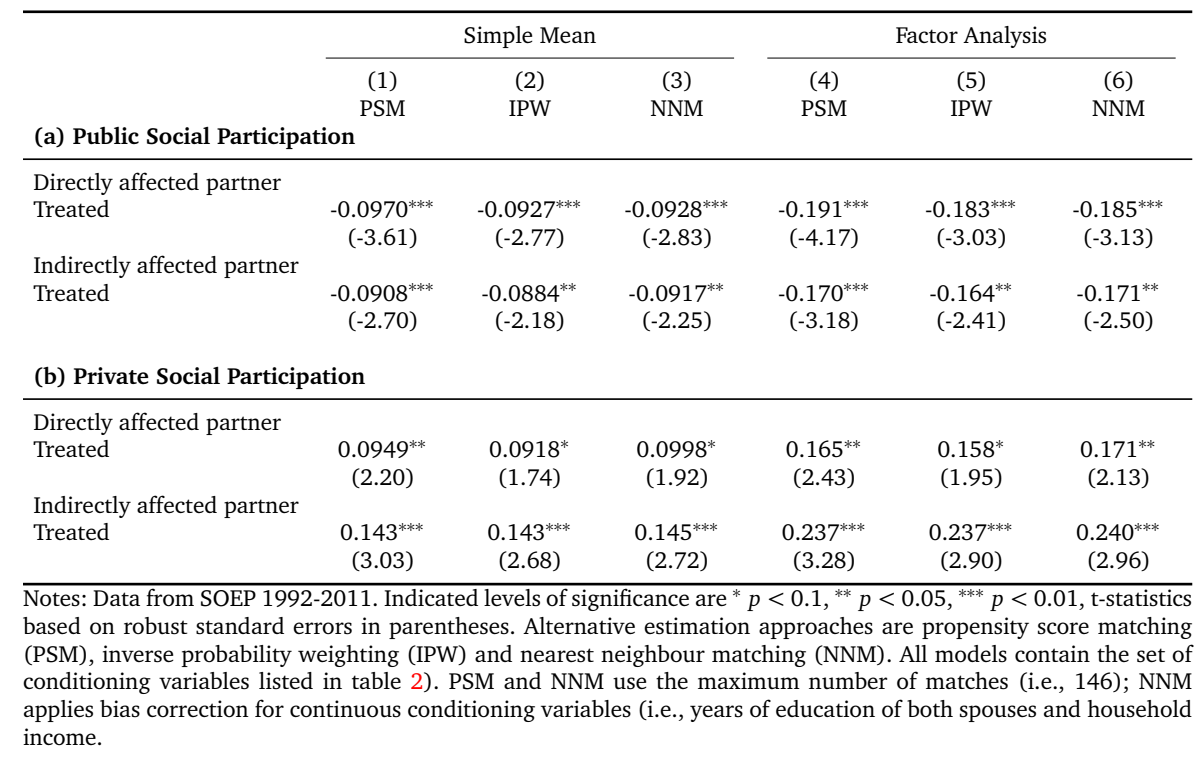


Table 5 Unemployment and Social Participation - Further Results

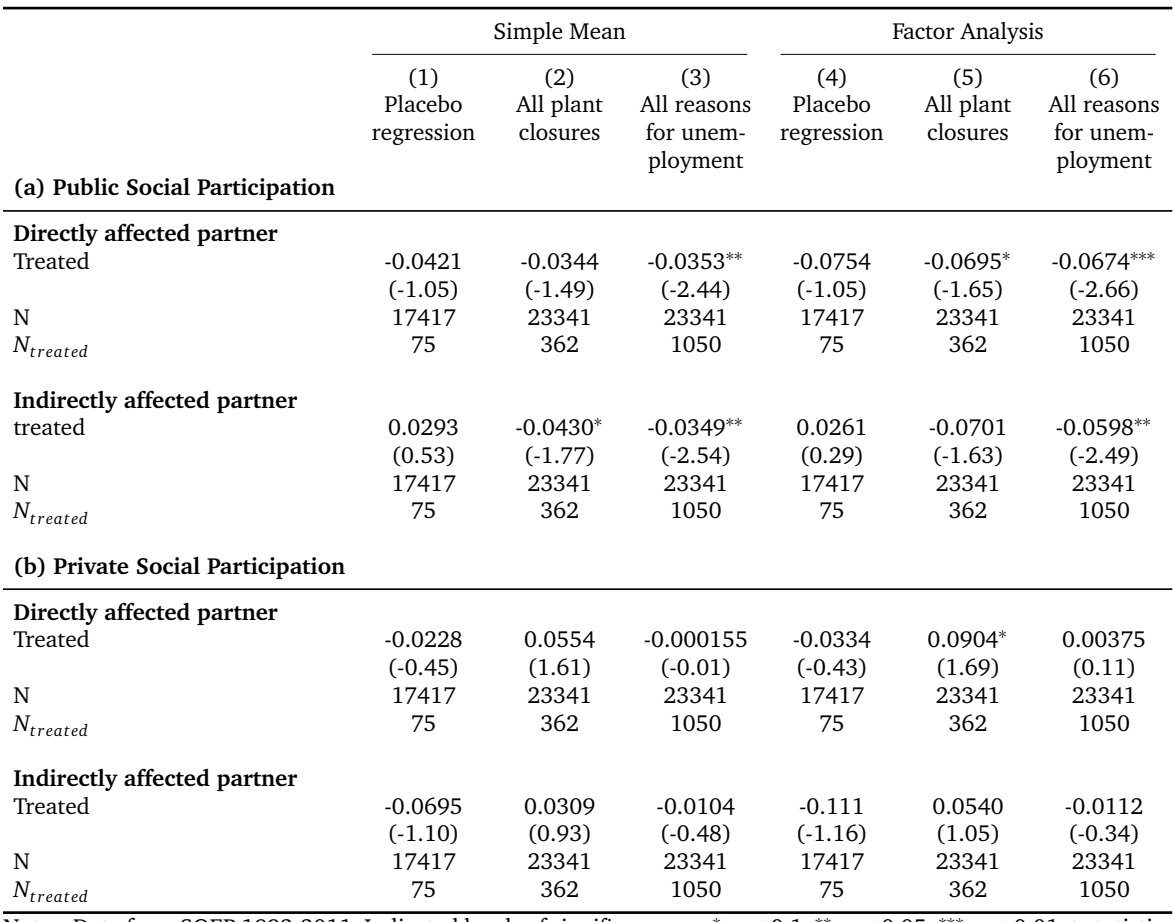

Notes: Data from SOEP 1992-2011. Indicated levels of significance are ${ }^{*} p<0.1{ }^{* *} p<0.05,{ }^{* * *} p<0.01$, t-statistics based on clustered standard errors (on the couple level) in parentheses. The table presents the effect of one spouse's entry into unemployment on the level of social participation of both spouses for private and public activities. Each cell displays the ATT from a separate regression (including all conditioning variables listed in table 2) based on the matching difference-in-differences estimator. Columns (1) and (4) present the results from a placebo regression in which the treatment is assumed to take place during the previous treatment period. Columns (2) and (5) show the results when all couples that experienced a plant closure (but necessarily an unemployment spell) are included in the treatment group. Columns (3) and (6) display the results when the treatment group includes couples with all reasons for unemployment (not just due to a plant closure).

Table 6 Unemployment and Social Participation - The Results for each Single Activity

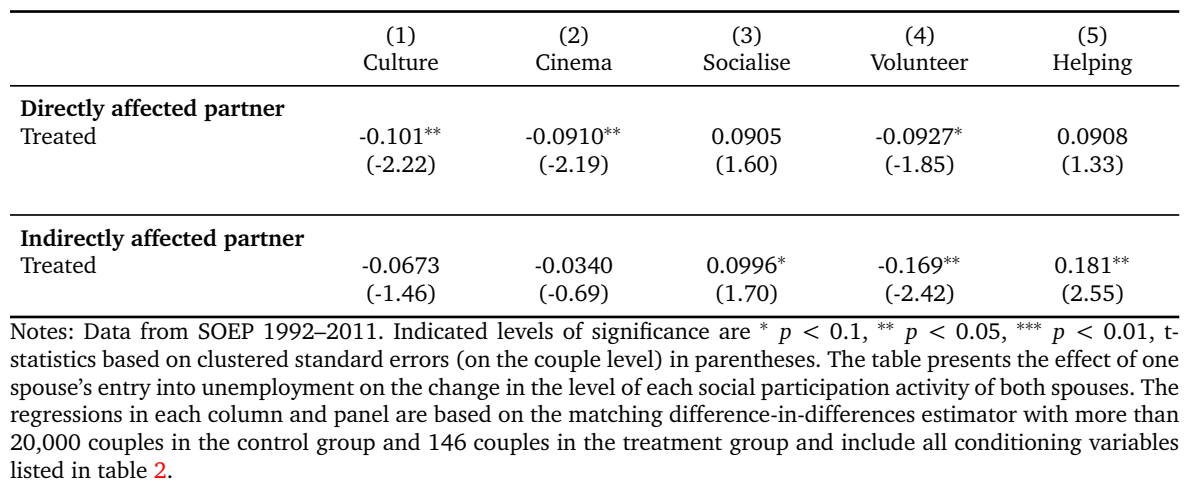

